\title{
Burden of air leak complications in thoracic surgery estimated using a national hospital billing database
}

This article was published in the following Dove Press journal:

ClinicoEconomics and Outcomes Research

29 June 2017

Number of times this article has been viewed

\section{Andrew Yoo' \\ Sudip K Ghosh ${ }^{2}$ \\ Walter Danker ${ }^{2}$ \\ Edmund Kassis ${ }^{3}$ \\ Iftekhar Kalsekar'}

'Medical Devices - Epidemiology, Johnson and Johnson, New Brunswick, ${ }^{2}$ Global Health Economics and Market Access, Ethicon Inc., Somerville, $\mathrm{N}$, ${ }^{3}$ Medical Affairs, Ethicon Inc., Cincinnati, $\mathrm{OH}$, USA
Correspondence: Andrew Yoo Medical Devices - Epidemiology, Johnson \& Johnson, 4I0 George Street, GSII3I, New Brunswick, NJ 0890I, USA

$\mathrm{Tel}+\mathrm{I} 7325241354$

Fax +l 7325245242

Email ayoo@its.jnj.com
Background: One of the most common outcomes of lung resections are parenchymal air leaks. These air leaks are most often self-limited and spontaneously resolve several days after surgery. Historically, only prolonged air leaks have been considered to have a significant effect on patient outcomes. This study aims to evaluate the impact of any air leak complications (aALCs) on resource utilization and mortality.

Methods: The Premier Perspective ${ }^{\circledR}$ database was used to identify all elective primary lobectomy, segmentectomy, and wedge resections performed from 2012 to 2014; aALC was defined as a composite of air leak and pneumothorax. Generalized estimating equation models were used to estimate the impact of aALCs on length of stay (LOS), operating room time (ORT), hospital costs, and mortality during index hospitalization.

Results: A total of 21,150 patients undergoing lung resection surgery were included in the analysis: lobectomy $(n=10,946)$, segmentectomy $(n=1,788)$, and wedge resection $(n=8,416)$. The overall incidence of aALCs was $24.26 \%$ (95\% CI [23.68, 24.83]). Identified risk factors included resection type, surgical approach, male gender, and presence of COPD. Patients with aALCs had a significantly higher economic burden (adjusted mean [standard error of mean, SE]: LOS=7.24 $[\mathrm{SE}=0.12]$ days; $\mathrm{ORT}=214.9$ [SE $=6.4] \mathrm{min}$; and hospital costs $=\$ 26,070$ [SE= $\$ 1404]$ ) compared to those without aALCs (adjusted mean [SE]: $\mathrm{LOS}=4.75$ [SE=0.07] days; ORT=201.7 [SE=3.9] min; and hospital costs $=\$ 19,558$ [SE $=\$ 399]$ ). aALC was also associated with increased overall index hospitalization mortality (odds ratio=1.90, 95\% CI [1.42, 2.55]).

Conclusion: This analysis showed that aALC are not only frequent but also associated with significantly higher resource utilization and mortality.

Keywords: lobectomy, segmentectomy, wedge resection, outcomes

\section{Introduction}

One of the most common outcomes of thoracic lung resections are air leaks arising from lung parenchyma. Postoperatively, the incidence of air leaks immediately after resection has been reported to range from $28 \%$ to $60 \%$ with the majority spontaneously resolving by postoperative day $4 .{ }^{1}$ Because most air leaks are self-limited, controlled with a standard chest tube, and spontaneously resolve several days after surgery, only prolonged air leaks (PALs) (lasting for $>5$ or 7 days) have been considered a surgical complication. ${ }^{1,2}$ This definition of PALs does not consider air leaks lasting $<5$ or 7 days but result in prolonged hospitalization. Additionally, this definition does not consider the type of lung resection. The expected length of stay (LOS) for wedge resections (4-7 days) is significantly less than that for lobectomy (6-10 days); thus, air leaks of shorter duration may be more important in wedge resections as they may contribute 
more often to additional hospital days. ${ }^{3-5}$ A more general definition of any air leak complications (aALCs) would include air leaks of any duration that result in a clinical intervention or prolonged hospitalization.

Research has focused on the clinical and economic effects of PALs with the incidence estimated at between $8 \%$ and $26 \%$ in patients undergoing major pulmonary resection. ${ }^{6-9}$ The incidence of PALs varies by resection type with segmentectomy having the highest incidence (10-15\%), followed by lobectomy (9-13\%) and wedge resection $(3.3 \%){ }^{6,10-14}$ COPD is one of the major risk factors for PALs. ${ }^{7,13,15} \mathrm{~A}$ PAL has been shown to be associated with a complicated postoperative course, a longer hospital stay, ${ }^{6}$ and higher rates of readmissions and other complications (such as pneumonia and respiratory failure). ${ }^{1,16}$ Because of the focus on PALs, there is a paucity of research evaluating the effect of any air leak and the potential impact on resource utilization.

Recent advances in surgical techniques (especially videoassisted thoracoscopic surgery, VATS $)^{17-20}$ and postoperative care (such as improved pain management ${ }^{21}$ and more optimal chest tube management ${ }^{22}$ ) have decreased morbidities and hospital LOS and facilitated rapid return to baseline functional levels. ${ }^{23,24}$ Because of this trend of shorter hospitalizations, air leaks that previously would have resolved prior to the patient being ready for discharge and have little noticeable impact on LOS may now contribute to prolonged hospitalization and subsequent complications. The incidence of aALCs and their impact on health care utilization have not been well studied. Hence, the objective of this study is to identify the risk factors of any air leak and evaluate its clinical impact and economic burden in patients undergoing thoracic surgery.

\section{Methods}

\section{Study design and cohort}

This retrospective cohort study utilized data on lung resections, performed from 2012 to 2014, present in the Premier Perspective $^{\circledR}$ database (Premier, Inc., Charlotte, NC, USA). The procedure codes of the International Classification of Diseases, Ninth Revision (ICD-9), were utilized to identify all patients who underwent elective primary lobectomy (32.41, $32.49)$, segmentectomy (32.30, 32.39), and wedge resections $(32.20,32.28,32.29)$ (Table S1).

\section{Database}

The Premier Perspective database utilized in this study is a hospital billing database that contains information on clinical coding, hospital cost, and patient billing data from $>600$ hospitals in the US. These hospitals are deemed nationally representative with respect to bed size, geographical region, location (urban/rural), and teaching hospital status. The database contains information on medications, laboratory and diagnostic procedures, and primary and secondary diagnoses for each patient's hospitalization. Approval by an Institutional Review Board was not necessary to conduct this study, as data within the Premier database are de-identified in accordance with the Health Insurance Portability and Accountability Act. No patient consent was required for this retrospective analysis.

\section{Inclusion and exclusion criteria}

Patients were included if they were undergoing elective thoracic lung resections (index), that is, wedge resection, segmentectomy, or lobectomy, regardless of the approach (VATS or thoracotomy), in an inpatient setting, and were 18 years or older at the time of index. Patients were excluded if the route of admission was transfer from a different facility or if they did not have an assigned discharge disposition. Additional exclusion criteria included evidence of pregnancy or if they underwent both a lobectomy and a segmentectomy procedure.

\section{Variables}

The primary outcomes of interests were hospital LOS, operating room time (ORT), overall hospital costs (adjusted to 2014 US dollars), and mortality. aALCs were defined as a composite of air leak (ICD-9 codes $=512.2,512.84$ ) and pneumothorax (ICD-9 codes $=512.1,512.89$ ) occurring at any time during the hospitalization. Unlike LOS and overall hospital costs, ORT temporally precedes aALCs within a patient's course of care. The objective of this study was to understand the health care utilization associated with aALCs irrespective of the temporal relationship, and hence, ORT was included in the analyses.

Other covariates assessed in this study are given as follows.

\section{Patients' demographic characteristics}

These included age, gender, race (categorized as White, Black, Hispanic, other, and unknown), and marital status (categorized as married, single, and other).

\section{Patients' comorbidities}

These included Charlson comorbidity score, which was assessed using Deyo-Charlson Comorbidity Index, and specific comorbidity categories, such as cardiac arrhythmia, congestive heart failure, peripheral vascular diseases, myocardial 
infarction, cardiovascular diseases, pulmonary circulation disorder, obesity, diabetes, hypertension, depression, renal failure, and COPD (Table S1). The Charlson Comorbidity Index $(\mathrm{CCI})$ is a method of categorizing comorbidities of patients based on the ICD diagnosis codes found in administrative data, such as hospital abstracts data. Each comorbidity category has an associated weight (from 1 to 6), based on the adjusted risk of mortality or resource use, and the sum of all the weights results in a single comorbidity score for a patient. The higher CCI score indicates higher likelihood that the predicted outcome will result in mortality or higher resource use. ${ }^{25}$

\section{Procedural characteristics}

These included payer type (categorized as commercial, Medicare, or Medicaid), year of surgery (2012, 2013, or 2014), surgical approach (VATS, thoracotomy), and robotic assistance.

\section{Provider characteristics}

These included location (urban/rural), teaching status (whether the hospital is a teaching hospital or not), geographical region (South, Northeast, Midwest, and West), hospital size (small, medium, large), bed size (categorized as 1-100 beds, $100-300$ beds, $301-500$ beds, and >500 beds), costing method ${ }^{26}$ (ratio of cost to charge vs procedural costing), hospital lung resection procedure volume from 2012 to 2014 (categorized as 1-50, 51-150, 151-300, and >300 surgeries), and physician specialty (categorized as thoracic surgeon, cardiac surgeon, general surgeon, or other).

\section{Statistical analysis}

Descriptive analysis (mean and standard deviation for continuous variables and proportions for categorical variables) was used to describe all the study variables. Bivariate analyses (Student's $t$-test and Chi square test) were conducted to assess the differences in outcomes for patients with and without aALCs. Risk factors for aALCs were analyzed utilizing logistic regression accounting for clustering within hospitals. Generalized estimating equation (GEE) models were used to explore the impact of aALCs on LOS, ORT, overall hospital costs, and mortality after accounting for clustering within hospitals and controlling for patient, provider, and procedure characteristics. All three models had a log link function. LOS and ORT were modeled with a negative binomial distribution, and overall hospital costs were modeled with a gamma distribution. The multivariable models evaluated the overall sample and also by resection type. A sensitivity analysis was performed to evaluate the effect of the present-on-admission (POA) flag. The POA flag, which indicates whether an ICD-9 diagnosis code was a preexisting comorbidity or an incident event, was utilized to identify aALC events. The incidence of aALCs was adjusted based on a revised algorithm that excluded aALCs with a POA flag, and GEE models were repeated with the revised algorithm. Statistical significance was set a priori at $p<0.05$ (two-sided). All analyses were conducted using SAS for Windows, Version 9.4 (SAS Institute Inc., Cary, NC, USA).

\section{Results}

Of the 21,150 patients, 10,946 underwent lobectomy $(46.4 \%$ VATS approach), 1,788 underwent segmentectomy $(62.4 \%$ VATS approach), and 8,416 underwent wedge resection (78.8\% VATS approach). Overall, 37\% of patients were 65 years or older with more females than males (53\% vs $47 \%$ ), and the majority were primarily White (76\%) and married (51\%). Hypertension was the most prevalent comorbid condition among this study population (61\%) followed by diabetes (21\%) and COPD (12\%). Tables 1 and 2 show the baseline patient and provider characteristics, respectively, by resection type. The mean (SD) LOS for all thoracic surgeries was 5.7 (5.4) days, with an average ORT of 211 (190) min and overall hospital costs of $\$ 22,163(\$ 83,619)$. The overall mortality was $1.06 \%$ (95\% CI $[0.92,1.20])$ and varied by resection type: lobectomy $1.42 \%(95 \%$ CI $[1.19,1.64])$, segmentectomy $0.95 \%$ (95\% CI $[0.50,1.40])$, and wedge resection $0.62 \%(95 \% \mathrm{CI}[0.45,0.79])$.

\section{Incidence and risk factors of aALCs}

The overall incidence of aALCs was $24.26 \%$ (95\% CI [23.68, $24.83]$ ) and varied by resection type: lobectomy $29.20 \%$ (95\% CI [28.35, 30.05]), segmentectomy 22.04\% (95\% CI $[20.11,23.96])$, and wedge resection $18.30 \%(95 \% \mathrm{CI}$ [17.47, 19.12]).

In the multivariable logistic regression analysis (presented in Figures 1 and 2), relevant risk factors for aALCs included the following: age group of 18-44 years compared to $\geq 75$ years (odds ratio $[\mathrm{OR}]=1.37,95 \% \mathrm{CI}[1.09,1.71]$ ), CCI scores of $0(\mathrm{OR}=0.65,95 \% \mathrm{CI}[0.56,0.76])$ and $3-4$ compared to $\geq 5$ $(\mathrm{OR}=1.26,95 \% \mathrm{CI}[1.16,1.37])$, procedures performed in year 2012 compared to 2014 (OR=0.85, 95\% CI [0.75, 0.97]), Northeast region compared to West $(\mathrm{OR}=0.69,95 \% \mathrm{CI}[0.50$, $0.96])$, thoracotomy approach compared to VATS (OR=1.13, 95\% CI [1.01, 1.27]), male gender (OR $=1.11,95 \%$ CI [1.04, $1.18])$, and the presence of COPD (OR=1.80 [1.63, 1.99]). Interestingly, other comorbidities including hypertension, 
Table I Baseline patient characteristics of the study cohort based on resection types

\begin{tabular}{|c|c|c|c|c|c|c|}
\hline \multirow[t]{2}{*}{ Patient characteristics } & \multicolumn{2}{|c|}{ Wedge $(n=8,4 \mid 6), \%$} & \multicolumn{2}{|c|}{ Segmentectomy $(n=I, 788), \%$} & \multicolumn{2}{|c|}{ Lobectomy $(n=10,946), \%$} \\
\hline & $\begin{array}{l}\text { Thoracotomy } \\
(n=I, 784)\end{array}$ & $\begin{array}{l}\text { VATS } \\
(n=6,632)\end{array}$ & $\begin{array}{l}\text { Thoracotomy } \\
(n=672)\end{array}$ & $\begin{array}{l}\text { VATS } \\
(n=1, I \mid 6)\end{array}$ & $\begin{array}{l}\text { Thoracotomy } \\
(n=5,870)\end{array}$ & $\begin{array}{l}\text { VATS } \\
(n=5,076)\end{array}$ \\
\hline \multicolumn{7}{|l|}{ Primary diagnosis } \\
\hline Cancer & 67.8 & 50.0 & 82.9 & 81.6 & $94.5 \%$ & $94.5 \%$ \\
\hline Pulmonary fibrosis & 10.5 & 19.3 & 3.1 & 5.1 & 0.7 & 0.9 \\
\hline Other & 21.7 & 30.7 & 14.0 & 13.3 & 4.8 & $4.5 \%$ \\
\hline \multicolumn{7}{|l|}{ Gender } \\
\hline Female & 51.2 & 53.9 & 49.1 & 53.8 & 50.3 & 55.4 \\
\hline \multicolumn{7}{|l|}{ Age (years) } \\
\hline $18-44$ & 6.0 & 9.4 & 5.2 & 3.7 & 2.4 & 2.1 \\
\hline $45-54$ & 12.3 & 13.8 & 9.1 & 9.2 & 9.5 & 9.6 \\
\hline $55-64$ & 25.4 & 24.7 & 27.5 & 21.7 & 25.9 & 23.7 \\
\hline $65-74$ & 34.5 & 32.3 & 34.8 & 37.4 & 39.6 & 39.8 \\
\hline $75+$ & 21.9 & 19.8 & 23.4 & 28.0 & 22.7 & 24.8 \\
\hline \multicolumn{7}{|l|}{ Race } \\
\hline White & 78.2 & 73.6 & 76.3 & 75.3 & 78.3 & 75.7 \\
\hline Black & 7.1 & 7.0 & 8.5 & 6.7 & 7.2 & 7.6 \\
\hline Other & 14.7 & 19.4 & 15.2 & 18.0 & 14.5 & 16.6 \\
\hline \multicolumn{7}{|l|}{ Marital status } \\
\hline Single & 36.0 & 34.1 & 37.4 & 35.1 & 36.6 & 36.1 \\
\hline Married & 52.1 & 50.3 & 48.5 & 50.1 & 53.2 & 47.6 \\
\hline Other & 11.9 & 15.6 & 14.1 & 14.8 & 10.2 & 16.3 \\
\hline \multicolumn{7}{|l|}{ Payer } \\
\hline Commercial & 32.3 & 38.4 & 31.7 & 31.0 & 29.1 & 30.3 \\
\hline Medicaid & 7.0 & 6.6 & 6.1 & 4.4 & 5.8 & 5.6 \\
\hline Medicare & 58.1 & 53.3 & 60.6 & 63.3 & 63.1 & 62.5 \\
\hline Other & 2.6 & 1.7 & 1.6 & 1.3 & 2.0 & 1.7 \\
\hline \multicolumn{7}{|l|}{ Year } \\
\hline 2012 & 38.3 & 34.0 & 39.7 & 35.7 & 35.6 & 32.0 \\
\hline 2013 & 31.4 & 31.8 & 29.2 & 31.4 & 34.6 & 32.6 \\
\hline 2014 & 30.2 & 34.2 & 31.1 & 33.0 & 29.8 & 35.4 \\
\hline \multicolumn{7}{|c|}{ Charlson Comorbidity Index } \\
\hline 0 & 14.1 & 20.4 & 6.5 & 8.2 & 3.2 & 4.0 \\
\hline $\mathrm{I}-2$ & 27.4 & 36.2 & 24.7 & 32.3 & 24.2 & 29.3 \\
\hline $3-4$ & 28.0 & 20.5 & 40.9 & 36.0 & 42.8 & 43.3 \\
\hline$\geq 5$ & 30.5 & 22.9 & 27.8 & 23.4 & 29.8 & 23.5 \\
\hline \multicolumn{7}{|c|}{ Specific comorbid condition } \\
\hline COPD & 11.94 & 11.05 & 13.69 & 12.01 & 12.16 & 10.87 \\
\hline Diabetes & 22.59 & 19.09 & 22.77 & 18.46 & 22.27 & 20.04 \\
\hline Hypertension & 60.87 & 54.60 & 63.69 & 60.30 & 64.96 & 62.55 \\
\hline Renal failure & 7.29 & 5.50 & 7.14 & 6.45 & 7.21 & 5.83 \\
\hline Obesity & 13.68 & 13.06 & 11.76 & 13.98 & 11.77 & 11.84 \\
\hline
\end{tabular}

Abbreviation: VATS, video-assisted thoracoscopic surgery.

obesity, and diabetes were associated with decreased odds of aALCs. Both segmentectomy $(\mathrm{OR}=0.77,95 \%$ CI $[0.67$, $0.89])$ and wedge resection $(\mathrm{OR}=0.73,95 \% \mathrm{CI}[0.66,0.80])$ had lower odds of aALCs compared to lobectomy.

\section{Impact of aALCs on health care utilization and mortality}

Results from the bivariate analysis showed that the unadjusted mean (SD) for LOS, ORT, and overall hospital costs for patients with and without aALCs was 8.07 (6.12) days vs 4.94 (4.83) days, 231 (245) min vs 205 (169) min, and $\$ 29,213(\$ 167,076)$ vs $\$ 19,905(\$ 16,509)$, respectively (all with $p<0.001)$. Unadjusted mortality was found to be $1.85 \%$ among patients with aALCs compared to $0.81 \%$ among patients without aALCs $(p<0.001)$. The differences in unadjusted means for LOS, ORT, mortality, and overall hospital costs remained significantly higher among patients with aALCs across types of resection.

The adjusted mean LOS (days) in the multivariable analysis was $42.2 \%$ longer for patients with aALCs compared to 
Table 2 Baseline provider characteristics of the study cohort based on resection types

\begin{tabular}{|c|c|c|c|c|c|c|}
\hline \multirow[t]{3}{*}{ Provider characteristics } & \multicolumn{2}{|c|}{ Wedge $(n=8,4 \mid 6), \%$} & \multicolumn{2}{|c|}{ Segmentectomy $(n=1,788), \%$} & \multicolumn{2}{|c|}{ Lobectomy $(n=10,946), \%$} \\
\hline & Thoracotomy & VATS & Thoracotom & VATS & Thoracotomy & VATS \\
\hline & $(n=I, 784)$ & $(n=6,632)$ & $y(n=672)$ & $(n=1, I 16)$ & $(n=5,870)$ & $(n=5,076)$ \\
\hline Teaching hospital & 45.0 & 61.0 & 47.8 & 58.5 & 45.5 & 62.9 \\
\hline \multicolumn{7}{|l|}{ Geographic area of USA } \\
\hline Midwest & 26.8 & 17.1 & 22.3 & 10.1 & 25.8 & 14.7 \\
\hline Northeast & 12.1 & 32.9 & 11.3 & 33.1 & 11.0 & 28.8 \\
\hline South & 47.4 & 36.1 & 47.8 & 43.4 & 46.9 & 43.0 \\
\hline West & 13.7 & 13.9 & 18.6 & 13.4 & 16.3 & 13.6 \\
\hline Urban hospital & 89.2 & 93.5 & 92.0 & 92.7 & 88.6 & 95.7 \\
\hline \multicolumn{7}{|l|}{ Hospital size } \\
\hline Small & 3.3 & 4.5 & 3.0 & 4.1 & 3.2 & 4.4 \\
\hline Medium & 12.8 & 12.7 & 14.1 & 12.6 & 12.7 & 11.6 \\
\hline Large & 83.9 & 82.8 & 82.9 & 83.2 & 84.1 & 84.1 \\
\hline \multicolumn{7}{|l|}{ Hospital bed size } \\
\hline Bed size $1-300$ & 28.7 & 19.4 & 22.0 & 23.2 & 23.0 & 17.2 \\
\hline Bed size $30 \mathrm{I}-500$ & 40.2 & 39.0 & 47.9 & 31.5 & 43.8 & 33.4 \\
\hline Bed size $>500$ & 31.1 & 41.7 & 30.1 & 45.3 & 33.2 & 49.4 \\
\hline \multicolumn{7}{|l|}{$\begin{array}{l}\text { Number of thoracic } \\
\text { surgeries }(2012-2014)\end{array}$} \\
\hline $\mathrm{I}-50$ & 30.7 & 17.1 & 26.6 & 16.0 & 26.0 & 13.3 \\
\hline $51-150$ & 42.8 & 41.7 & 42.9 & 42.8 & 46.6 & 45.3 \\
\hline $151-300$ & 20.7 & 20.4 & 26.9 & 17.9 & 23.0 & 20.4 \\
\hline$>300$ surgeries & 5.8 & 20.8 & 3.6 & 23.2 & 4.4 & 21.0 \\
\hline \multicolumn{7}{|l|}{ Cost type } \\
\hline Procedural & 74.9 & 72.4 & 72.0 & 67.7 & 75.7 & 73.0 \\
\hline $\mathrm{RCC}$ & 25.1 & 27.6 & 28.0 & 32.3 & 24.3 & 27.0 \\
\hline \multicolumn{7}{|l|}{ Physician specialty } \\
\hline Thoracic surgeon & 63.1 & 64.4 & 65.0 & 65.1 & 63.3 & 64.1 \\
\hline Cardiac surgeon & 19.8 & 13.6 & 16.7 & 9.3 & 20.1 & 13.4 \\
\hline General surgeon & 10.3 & 14.3 & 10.0 & 13.4 & 9.1 & 11.6 \\
\hline Other & 6.8 & 7.6 & 8.3 & 12.3 & 7.6 & 10.9 \\
\hline
\end{tabular}

Abbreviations: VATS, video-assisted thoracoscopic surgery; RCC, ratio of cost to charge.

those without aALCs (Figure 3). The adjusted mean ORT (min) was $6.4 \%$ longer for patients with aALCs compared to those without aALCs (Figure 4). Overall, the adjusted hospital costs were $28.7 \%$ higher among patients with aALCs compared to those without aALCs (Figure 5). These were all statistically significant differences. Overall, aALCs were associated with increased odds of mortality (OR=1.90, 95\% CI $[1.42,2.55])$. Within lobectomy (OR $=3.40,95 \%$ CI $[1.88$, $6.15])$ and wedge resection $(\mathrm{OR}=1.50,95 \% \mathrm{CI}[1.07,2.10])$, aALC was associated with significantly increased mortality, but no differences in segmentectomy $(\mathrm{OR}=2.05,95 \% \mathrm{CI}$ $[0.67,6.25]$ ) were observed (Figure 6).

In the sensitivity analysis, the incidence of aALCs was adjusted by excluding cases which were POA. This slightly reduced the incidence rates of aALCs (overall $=21.91 \%$; lobectomy $=27.30 \%$; segmentectomy $=19.97 \%$; wedge resection $=15.32 \%$ ). However, the consequent impact on resource utilization was consistent. The overall incidence of
aALCs varied by type of approach (thoracotomy=27.88\% vs VATS $=21.90 \%$ ), and the impact on resource utilization within each type of approach was similar to the overall cohort. The costs for one of the patients in the study cohort with aALC were an outlier with the hospital cost of \$11.9 million. Reanalysis of the data after excluding this patient led to consistent results for ORT and LOS. Costs were also significantly higher for the aALCs cohort, but the incremental adjusted costs decreased from $\$ 6,338$ to $\$ 5,054$.

\section{Discussion}

This study aimed to address the gap in the available literature by providing more evidence on the impact of aALCs on health care utilization and mortality. To the best of knowledge, this study is the first to describe the significant burden of aALCs on hospital costs along with increased LOS and longer ORT. A longer ORT may represent a more complex operation with increased tissue manipulation and dissection which may be 
COPD*

Age $18-44$ vs $5+^{*}$

CCl score 3-4 vs $5+^{*}$

Other vs cancer

Males vs females

Other vs Whites

Other vs single

CCl score $1-2$ vs $5+^{*}$

Age $65-74$ vs $75+$

Depression*

African American vs White

Medicare vs other

Married vs single

Age 45-54 vs 75+

Medicaid vs other

Commercial vs other

Hypertension*

Age 55-64 years vs 75+

Diabetes*

Pulmonary fibrosis vs cancer

$\mathrm{CCl}$ score 0 vs $5+^{*}$

Obesity*

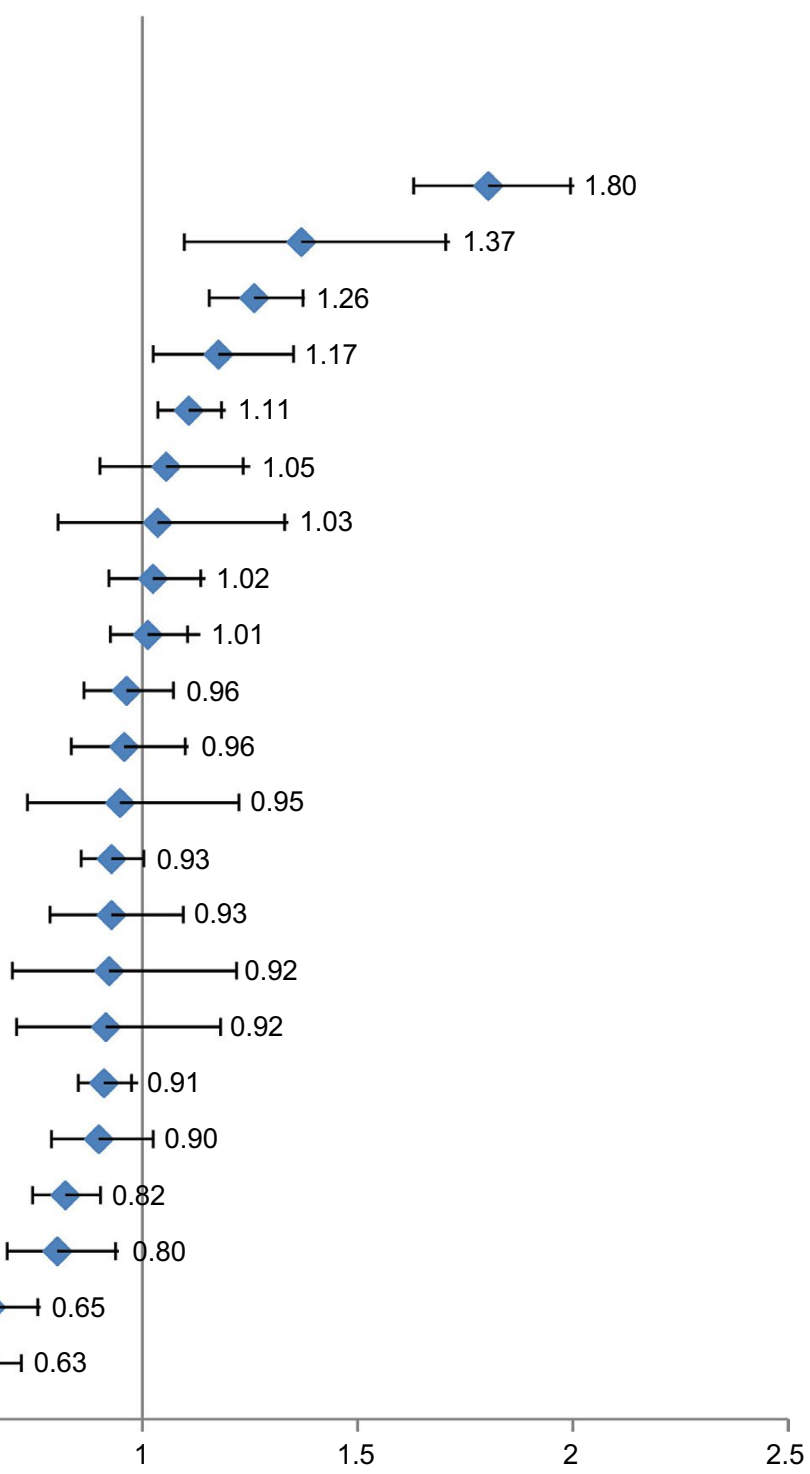

Figure I Patient-related factors associated with aALC.

Notes: Values represent odds ratios, and error bars represent $95 \% \mathrm{Cls}$. ${ }^{*}$ Charlson Comorbidity Index. ${ }^{25}$

Abbreviations: aALC, any air leak complication; $\mathrm{CCl}$, Charlson Comorbidity Index.

risk factors for aALCs. This study shows that aALCs are frequent events, occurring in $24 \%$ of all lung resections with an associated increase in LOS of 2.5 days and hospital costs of $\$ 6,000$. Additionally, the study found that aAC is associated with a significant increase in the odds of mortality. This finding differs from prior studies that evaluated PALs. This difference may be attributed to the air leak duration ( 5 or 7 days) requirement, which requires hospitalization during this period and is inherently biased in overestimating the effect on health care utilization.

The overall incidence of aALCs was nearly $24 \%$ and is within the range of the published literature for any air leaks $(26 \%-48 \%){ }^{22,27,28}$ Additionally, this aALC estimate is lower than reported PALs. A study conducted by Varela et al found the incidence of PALs ( $>5$ days) to be $\sim 10 \%,{ }^{11}$ while others have reported the incidence in the range of $15 \%-18 \% .^{13,29}$ The present study identified multiple risk factors for aALCs including thoracotomy, male gender, lobectomy resections, and the presence of COPD. These are similar to risk factors identified in clinical studies. ${ }^{30-32}$ Bille et $\mathrm{al}^{27}$ identified multiple anatomic risk factors including resection type, pleural adhesions, and an incomplete fissure. Brunelli et al ${ }^{13}$ identified risk factors for PALs after lobectomy including reduced postoperative forced expiratory volume in 1 second (FEV1), pleural adhesions, and upper lobe resections. Cerfolio et al ${ }^{33}$ found FEV1, steroid use, male gender, and lobectomy resections as risk factors for air leaks. Surprisingly in the present study, diabetes, hypertension, and obesity were associated 
$50-150$ vs $300+$ resection

Approach: open vs VATS

Rural vs Urban

Bed size: $301-500$ vs $500+$ beds

Bed size: $1-300$ vs $500+$ beds

Procedural vs RCC costing

Midwest vs West USA

Cardiovascular vs thoracic surgeon

Other vs thoracic surgeon

Teaching vs nonteaching

Year 2013 vs 2014

General vs thoracic surgeon

$151-300$ vs $300+$ lung resections

$1-50$ vs $300+$ lung resections

South vs West USA

Year 2012 vs 2014

Segmentectomy vs lobectomy

Wedge vs lobectomy

Northeast vs West USA
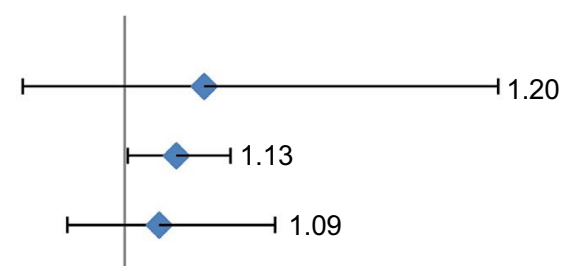


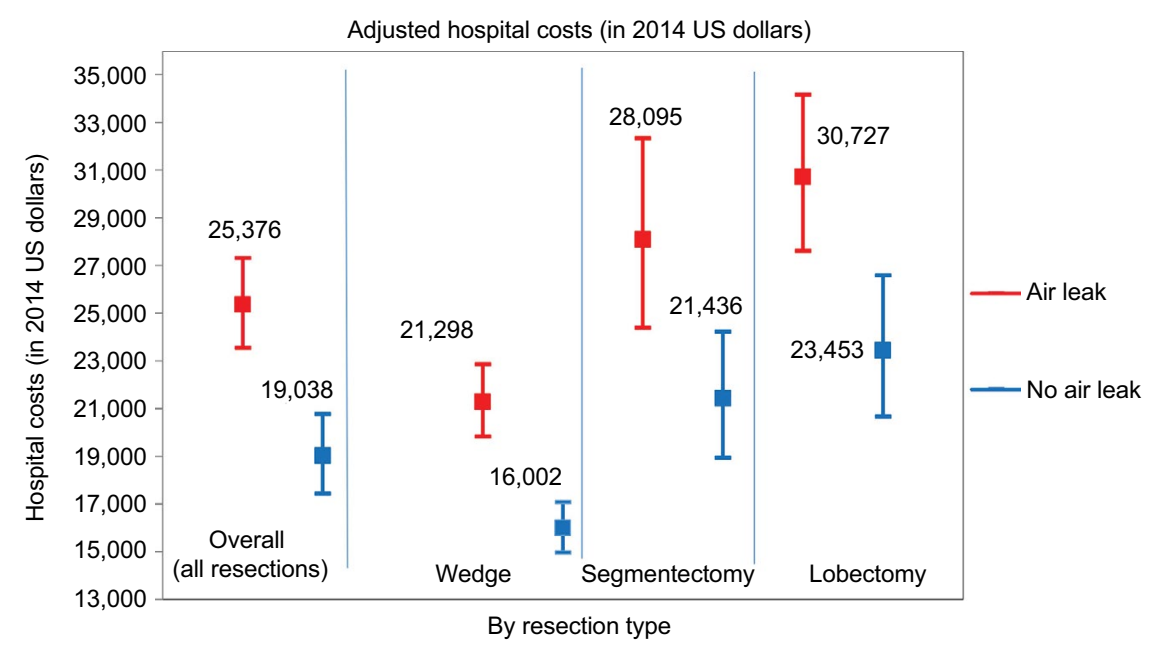

Figure 5 Association between air leak and hospital costs (overall and by resection type).

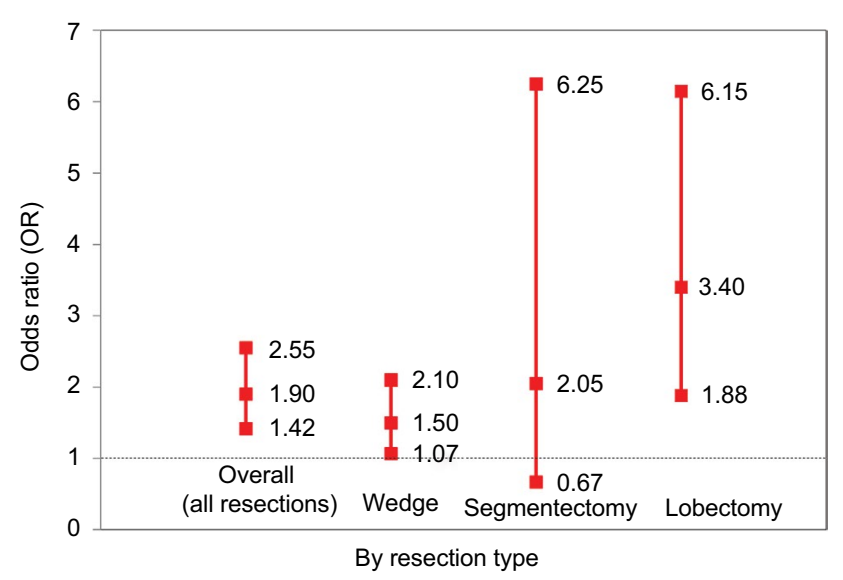

Figure 6 Association between any air leak complications and mortality.

with decreased odds of aALCs. While these have not been previously shown to be risk factors for PALs, this may reflect differences in surgeon expectations or coding practices for patients with these comorbidities.

This study found that patients with aALCs were associated with a significantly increased mean LOS, a finding consistent with other previously published studies. ${ }^{10,34-36} \mathrm{~A}$ retrospective case series conducted by Bardell and Petsikas found that the only significant predictor of increased LOS following pulmonary resection was air leaks lasting longer than 3 days. The mean postoperative LOS for patients with PALs was 9.4 days compared to 5.2 days. ${ }^{34}$ Similarly, Liang et al found that the median hospital stay was prolonged by 4 days due to PALs ( $>5$ days). ${ }^{36}$ In a retrospective study of the Medicare Provider Analysis and Review Hospital National Limited Data Set, Wood et $\mathrm{al}^{9}$ analyzed the effect of air leaks in VATS lobectomy, segmentectomy, and lung volume reduction surgery performed in 2012. The rate of air leaks was $13.6 \%$ and increased LOS by $37 \%$ and hospital costs by $14.9 \%$. LOS for cases with a PAL was on average 2.7 days longer than those cases without an air leak diagnosis (10.0 days vs 7.3 days, respectively; $p<0.001)$. While most studies have reported the burden of air leaks in terms of LOS and mortality, only the study by Wood et al characterized the direct costs related to air leaks in the US. Similar to the present study, this study found a significantly higher total hospital costs in the air leaks group (\$22,641 vs $\$ 18,852) .{ }^{9}$ In this study, the hospital costs were calculated using the Inpatient Prospective Payment System Final Rule 2014 Standardizing File. Overall, the findings of the present study appear to show a similar association between aALCs and increased resource utilization.

Limitations of the present study are related to the use of a hospital billing database for the purpose of studying clinical outcomes research. The Premier database does not include an ICD-9 diagnosis date, so the exact onset and duration of aALCs is unknown. This makes it impossible to evaluate whether the effects seen are related to shorter duration vs PALs (e.g. PALs). Additionally, important clinical risk factors such patient body mass index, prior neo-adjuvant chemoradiation, preoperative lung function (such as forced expiratory volume), tumor size or stage, lung lobe anatomy, intraoperative pleural adhesions, and tissue quality are not available. These unmeasured patient differences may be correlated with aALCs and contribute to the increased resource utilization observed. The present analysis excluded nonelective cases which are $\sim 20 \%$ of thoracic lung resections in the Premier sample. This proportion of elective to nonelective procedures is consistent with other published studies. ${ }^{37,38}$ Finally, the Premier hospital database captures $\sim 20 \%$ of annual US 
inpatient discharges or $>80$ million inpatient admissions with $>5$ million per year since 2011 and has been described as a representative sample of inpatient admissions. ${ }^{39}$ The results from this study may not be completely representative of the costs and outcomes across the entire US.

\section{Conclusion}

The potential importance of shorter-duration air leaks may increase as improvements in surgical techniques and postoperative care continue to decrease the average length of hospital stay of patients after thoracic resections. Based upon these findings, the prevention and management of any air leak regardless of duration may be an important outcome to consider for improvements in clinical practice.

In conclusion, aALCs in patients undergoing lung resections are not only frequent but also associated with significant impacts on patient outcomes in terms of LOS, total hospital costs, and mortality.

\section{Acknowledgments}

The authors would like to thank Surbhi Shah, M.S., and Monali Bhosle, Ph.D., from Outcomes Inc. for their medical writing support. This study was funded by Johnson and Johnson, Brunswick, NJ, USA. The study was presented as a poster at the annual international meeting of the International Society for Pharmacoeconomics and Outcomes Research (ISPOR) held in May 2016 in Washington, DC, USA.

The study was funded by Johnson \& Johnson.

\section{Disclosure}

Drs Yoo and Kalsekar are employees of Johnson \& Johnson. Drs Ghosh, Danker, and Kassis are employees of Ethicon, Inc., which is a subsidiary of Johnson \& Johnson.

\section{References}

1. Mueller MR, Marzluf BA. The anticipation and management of air leaks and residual spaces post lung resection. $J$ Thorac Dis. 2014;6(3):271-284.

2. The Society of Thoracic Surgeons. Data collection. Available from: http://www.sts.org/quality-research-patient-safety/national-database/ database-managers/general-thoracic-surgery-databa-1. Accessed October 10, 2016.

3. Landreneau RJ, Sugarbaker DJ, Mack MJ, et al. Wedge resection versus lobectomy for stage I (T1 N0 M0) non-small-cell lung cancer. J Thorac Cardiovasc Surg. 1997;113(4):691-700.

4. David G, Gunnarsson CL, Moore M, et al. Surgeon's volume-outcome relationship for lobectomies and wedge resections for cancer using video-assisted thoracoscopic techniques. Minim Invasive Surg. 2012;2012:760292.

5. Lacin T, Swanson S. Current costs of video-assisted thoracic surgery (VATS) lobectomy. J Thorac Dis. 2013;5(3):S190-S193.

6. Okereke I, Murthy SC, Alster JM, Blackstone EH, Rice TW. Characterization and importance of air leak after lobectomy. Ann Thorac Surg. 2005;79(4):1167-1173.
7. Stolz AJ, Schutzner J, Lischke R, Simonek J, Pafko P. Predictors of prolonged air leak following pulmonary lobectomy. Eur J Cardiothorac Surg. 2005;27(2):334-336.

8. Abolhoda A, Liu D, Brooks A, Burt M. Prolonged air leak following radical upper lobectomy: an analysis of incidence and possible risk factors. Chest. 1998;113(6):1507-1510.

9. Wood DE, Lauer LM, Layton A, Tong KB. Prolonged length of stay associated with air leak following pulmonary resection has a negative impact on hospital margin. Clinicoecon Outcomes Res. 2016;8:187-195. Erratum in: Clinicoecon Outcomes Res. 2016;8:351.

10. Brunelli A, Xiume F, Al Refai M, Salati M, Marasco R, Sabbatini A. Air leaks after lobectomy increase the risk of empyema but not of cardiopulmonary complications: a case-matched analysis. Chest. 2006;130(4): $1150-1156$.

11. Varela G, Gimenez MF, Novoa N, Aranda JL. Estimating hospital costs attributable to prolonged air leak in pulmonary lobectomy. Eur $J$ Cardiothorac Surg. 2005;27(2):329-333.

12. Rivera C, Bernard A, Falcoz PE, et al. Characterization and prediction of prolonged air leak after pulmonary resection: a nationwide study setting up the index of prolonged air leak. Ann Thorac Surg. 2011;92(3): 1062-1068.

13. Brunelli A, Monteverde M, Borri A, Marasco RD, Fianchini A. Predictors of prolonged air leak after pulmonary lobectomy. Ann Thorac Surg. 2004;77(4):1205-1210.

14. Kuroda H, Dejima H, Mizumo T, Sakakura N, Sakao Y. A new LigaSure technique for the formation of segmental plane by intravenous indocyanine green fluorescence during thoracoscopic anatomical segmentectomy. J Thorac Dis. 2016;8(6):1210-1216.

15. Singhal S, Ferraris VA, Bridges CR, et al. Management of alveolar air leaks after pulmonary resection. Ann Thorac Surg. 2010;89(4): 1327-1335.

16. Seely AJ, Ivanovic J, Threader J, et al. Systematic classification of morbidity and mortality after thoracic surgery. Ann Thorac Surg. 2010;90(3): 936-942.

17. Cao C, Manganas C, Ang SC, Peeceeyen S, Yan TD. Video-assisted thoracic surgery versus open thoracotomy for non-small cell lung cancer: a meta-analysis of propensity score-matched patients. Interact Cardiovasc Thorac Surg. 2013;16(3):244-249.

18. Paul S, Altorki NK, Sheng S, et al. Thoracoscopic lobectomy is associated with lower morbidity than open lobectomy: a propensitymatched analysis from the STS database. J Thorac Cardiovasc Surg. 2010;139(2):366-378

19. Scott WJ, Allen MS, Darling G, et al. Video-assisted thoracic surgery versus open lobectomy for lung cancer: a secondary analysis of data from the American College of Surgeons Oncology Group Z0030 randomized clinical trial. JThorac Cardiovasc Surg. 2010;139(4):976-983.

20. Swanson SJ, Meyers BF, Gunnarsson CL, et al. Video-assisted thoracoscopic lobectomy is less costly and morbid than open lobectomy: a retrospective multiinstitutional database analysis. Ann Thorac Surg. 2012;93(4):1027-1032.

21. Landreneau RJ, Hazelrigg SR, Mack MJ, et al. Postoperative pain-related morbidity: video-assisted thoracic surgery versus thoracotomy. Ann Thorac Surg. 1993;56(6):1285-1289.

22. Cerfolio RJ, Tummala RP, Holman WL, et al. A prospective algorithm for the management of air leaks after pulmonary resection. Ann Thorac Surg. 1998;66(5):1726-1731.

23. Ikeda N, Saji H, Haqiwara M, Ohira T, Usuda J, Kajiwara N. Recent advances in video-assisted thoracoscopic surgery for lung cancer. Asian J Endosc Surg. 2013;6(1):9-13.

24. Paoletti L, Pastis NJ, Denlinger CE, Silvestri GA. A decade of advances in treatment for early stage lung cancer. Clin Chest Med. 2011;32(4):827-838.

25. Deyo RA, Cherkin DC, Ciol MA. Adapting a clinical comorbidity index for use with ICD-9-CM administrative databases. J Clin Epidemiol. 1992;45(6):613-619.

26. Azoulay A, Doris NM, Filion KB, Caron J, Pilote L, Eisenberg MJ. The use of the transition cost accounting system in health services research. Cost Eff Resour Alloc. 2007;5:11 
27. Bille A, Borasio P, Gisabella M, et al. Air leaks following pulmonary resection for malignancy: risk factors, qualitative and quantitative analysis. Interact Cardiovasc Thorac Surg. 2011;13(1):11-15.

28. Brunelli A, Monteverde M, Borri A, et al. Comparison of water seal and suction after pulmonary lobectomy: a prospective, randomized trial. Ann Thorac Surg. 2004;77(6):1932-1937.

29. Isowa N, Hasegawa S, Bando T, Wada H. Preoperative risk factors for prolonged air leak following lobectomy or segmentectomy for primary lung cancer. Eur J Cardiothorac Surg. 2002;21(5):951.

30. Fernandes EO, Teixeira C, Da Silva LCC. Thoracic surgery: risk factors for postoperative complications of lung resection. Rev Assoc Med Bras (1992). 2011;57(3):292-298.

31. Pei G, Zhou S, Han Y, Liu Z, Xu S. Risk factors for postoperative complications after lung resection for non-small cell lung cancer in elderly patients at a single institution in China. J Thorac Dis. 2014;6(9):1230-1238.

32. Shiono S, Abiko M, Sato T. Postoperative complications in elderly patients after lung cancer surgery. Interact Cardiovasc Thorac Surg. 2013;16(6):819-823.

33. Cerfolio RJ, Bass CS, Pask AH, Katholi CR. Predictors and treatment of persistent air leaks. Ann Thorac Surg. 2002;73(6):1727-1731.
34. Bardell T, Petsikas D. What keeps postpulmonary resection patients in hospital? Can Respir J. 2003;10(2):86-89.

35. Irshad K, Feldman LS, Chu VF, Dorval JF, Baslaim G, Morin JE. Causes of increased length of hospitalization on a general thoracic surgery service: a prospective observational study. Can J Surg. 2002;45(4): 264-268.

36. Liang S, Ivanovic J, Gilbert S. Quantifying the incidence and impact of postoperative prolonged alveolar air leak after pulmonary resection. J Thorac Cardiovasc Surg. 2013;145(4):948-954.

37. Wakeam E, Hyder JA, Lipsitz SR, Darling GE, Finlayson SR. Outcomes and costs for major lung resection in the United States: which patients benefit most from high-volume referral? Ann Thorac Surg. 2015;100(3): 939-946.

38. Obirieze AC, Kisat M, Hicks CW, et al. State by state variation in emergency versus elective colon resections: room for improvement. J Trauma Acute Care Surg. 2013;74(5):1286-1291.

39. Premier Healthcare Database Whitepaper. Premier hospital database: data that informs and performs. Available from: https://www.premierinc. com/wpdm-package/research/. Accessed April 25, 2017. 


\section{Supplementary material}

Table SI List of diagnosis and procedure codes

\begin{tabular}{|c|c|c|c|}
\hline ICD-9 code & Definition & Resection type & Approach \\
\hline 32.20 & Thoracoscopic excision of lesion or tissue of lung & Wedge & VATS \\
\hline 32.28 & $\begin{array}{l}\text { Endoscopic excision or destruction of lesion or tissue } \\
\text { of lung }\end{array}$ & Wedge & VATS \\
\hline 32.29 & $\begin{array}{l}\text { Other local excision or destruction of lesion or tissue } \\
\text { of lung }\end{array}$ & Wedge & Open \\
\hline 32.30 & Thoracoscopic segmental resection of lung & Segmentectomy & VATS \\
\hline 32.39 & Other and unspecified segmental resection of lung & Segmentectomy & Open \\
\hline 32.41 & Thoracoscopic lobectomy of lung & Lobectomy & VATS \\
\hline 32.49 & Other lobectomy of lung & Lobectomy & Open \\
\hline 32.50 & Thoracoscopic pneumonectomy & Pneumonectomy & VATS \\
\hline 32.59 & Other and unspecified pneumonectomy & Pneumonectomy & Open \\
\hline \multicolumn{4}{|c|}{ Primary outcomes (ICD-9 diagnosis codes) for any air leak complication } \\
\hline ICD-9 code & Definition & \multicolumn{2}{|c|}{ Complication type } \\
\hline 512.2 & Postoperative air leak & \multicolumn{2}{|l|}{ Air leak } \\
\hline 512.84 & Other air leak & \multicolumn{2}{|l|}{ Air leak } \\
\hline 512.1 & latrogenic pneumothorax & \multicolumn{2}{|l|}{ Pneumothorax } \\
\hline 512.89 & Other pneumothorax & \multicolumn{2}{|l|}{ Pneumothorax } \\
\hline \multicolumn{4}{|c|}{ Coding algorithm for Charlson comorbidities ${ }^{25}$} \\
\hline \multicolumn{2}{|l|}{ ICD-9 code } & \multicolumn{2}{|l|}{ Comorbidities } \\
\hline \multicolumn{2}{|l|}{$4|0 . x, 4| 2 . x$} & \multicolumn{2}{|c|}{ Myocardial infarction } \\
\hline \multicolumn{2}{|l|}{ 428.x } & \multicolumn{2}{|c|}{ Congestive heart failure } \\
\hline \multicolumn{2}{|c|}{$443.9,441 . x, 785.4$, V43.4 procedure 38.48} & \multicolumn{2}{|c|}{ Peripheral vascular disease } \\
\hline \multicolumn{2}{|c|}{$430 . x-438 . x$} & \multicolumn{2}{|c|}{ Cerebrovascular disease } \\
\hline \multicolumn{2}{|l|}{ 290.x } & \multicolumn{2}{|l|}{ Dementia } \\
\hline \multicolumn{2}{|c|}{$490 . x-505 . x, 506.4$} & \multicolumn{2}{|c|}{ Chronic pulmonary disease } \\
\hline \multicolumn{2}{|c|}{$7|0.0,7| 0.1,7|0.4,7| 4.0-7|4.2,7| 4.8 \mid, 725 . x$} & \multicolumn{2}{|c|}{ Rheumatic disease } \\
\hline \multicolumn{2}{|c|}{$531 . x-534 . x$} & \multicolumn{2}{|c|}{ Peptic ulcer disease } \\
\hline \multicolumn{2}{|c|}{$57|.2,57| .4-57 \mid .6$} & \multicolumn{2}{|c|}{ Mild liver disease } \\
\hline \multicolumn{2}{|c|}{$250.0-250.3,250.7$} & \multicolumn{2}{|c|}{ Diabetes without chronic complication } \\
\hline \multicolumn{2}{|c|}{$250.4-250.6$} & Diabetes with chr & \\
\hline 344.I, 342.x & & Hemiplegia or par & \\
\hline $582 . x, 583-58$ & 585.x, 586.x, 588.x & Renal disease & \\
\hline $140 . x-172 . x, 1$ & $-195.8,200 . x-208 . x$ & $\begin{array}{l}\text { Any malignancy, in } \\
\text { neoplasm of skin }\end{array}$ & ind leukemia, except malignant \\
\hline 456.0-456.2I, & $.2-572.8$ & Moderate or sever & \\
\hline $196 . x-199.1$ & & Metastatic solid tu & \\
\hline $042 . x-044 . x$ & & AIDS/HIV & \\
\hline
\end{tabular}

Note: Only select comorbidities based on bivariate analysis were included in the regression models.

Abbreviations: ICD-9, International Classification of Diseases, Ninth Revision; VATS, video-assisted thoracoscopic surgery.

ClinicoEconomics and Outcomes Research

\section{Publish your work in this journal}

ClinicoEconomics and Outcomes Research is an international, peerreviewed open-access journal focusing on health technology assessment, pharmacoeconomics and outcomes research in the areas of diagnosis, medical devices, and clinical, surgical and pharmacological intervention. The economic impact of health policy and health systems
Dovepress

organization also constitute important areas of coverage. The manuscript management system is completely online and includes a very quick and fair peer-review system, which is all easy to use. Visit http://www.dovepress.com/testimonials.php to read real quotes from published authors. 